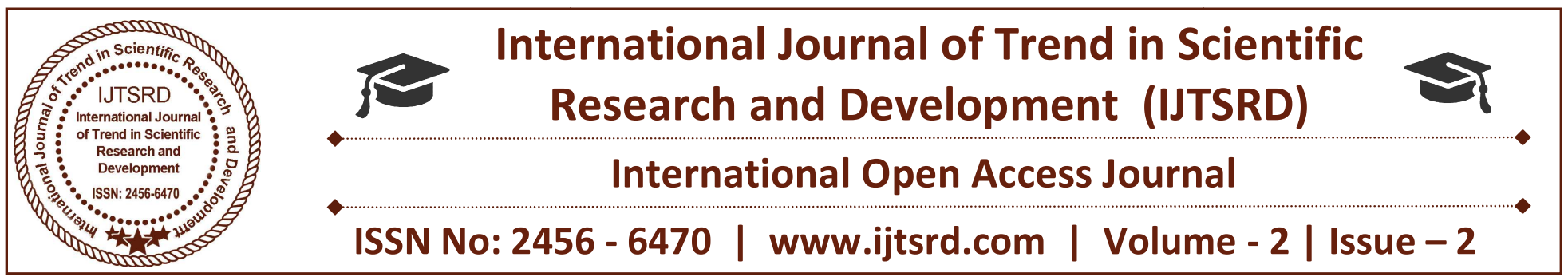

\title{
Dynamics of Deviant Behaviour on the Academic Participation of Early Adolescents, Limbe Sub-Division, South West Region of Cameroon
}

\author{
Patrick Fonyuy Shey, Ph.D \\ Department of Educational Psychology, \\ University of Buea, Cameroon
}

\author{
Tani Emmanuel Lukong, Ph.D \\ Department of Educational Psychology, \\ University of Buea, Cameroon
}

\section{ABSTRACT}

Once students enter the school setting, their behaviors, interpersonal relations, and emotional adjustments contribute to their successful academic development. Positive school behaviors and interpersonal relations represent good adjustments in the school setting, whereas negative school behaviors and interpersonal relations represent poor school adjustments. The purpose of this study was to assess the influence of deviant behaviour on the academic achievement of early adolescents in the Limbe I Sub Division. This study used the descriptive survey as a design for the research study. The main instruments used were the questionnaire an interview and observation. Purposive sampling was adopted. Three secondary schools were selected. A pilot study was used on one school to improve on the clarity and relevance of the instruments. The study revealed that deviant behaviour has a very detrimental effect on academic achievement of students. Most teachers use corporal punishment as a means of managing deviant behaviour in schools. The teachers used exclusion as the last resort to pupils who have deviant behaviour. The Results also indicated that individual inattentive behaviors and classroom-level of externalizing behaviors negatively and significantly predicted academic performance three years later. Overall, results here confirmed the previous literature supporting the negative effects of inattentive behaviors and classroom-level externalizing behaviors on the students' academic grades and achievement test scores. Therefore, indicators of deviant behavior (aggression, withdrawal and bullying) had an influence on the academic achievement of students with deviant behaviours. Recommendations were made to teachers, parents and other stakeholders to help curb deviant beaviours not just in schools but at home and in the community.

Keywords: Deviant Behaviour, Academic participation, Early Adolescents

\section{Introduction}

In the current age of educational reform, deviant behaviors of students have become an emerging issue for educators, policy makers and school administrators all over the world. Here the terms "deviant behaviors" "disruptive behavior" 'behavioural disorders or Problem Behavior, used interchangeably implies emotional and behavioral adjustment problems of students. Such problems not only impede educational, personal and social development of students but also may results in lifelong impairment functioning in social and personal life (Rutter, 1996). All over the world, there is no singular universal definition of deviant behaviors (Opong, 2008). More so, there are divergent views of the term and construct; while some scholars believed that a deviant behavior is the same as emotional behavioural disorders. Kauffman, (2001) holds that both words are synonymous and connote same meaning. He strongly believed that the different 
definitions are due to teacher's options, their background, cultural values, personalities and religious views. More often than expected, the behavior of some students within the school settings could pose a serious challenge to any teacher.

In the South West region of Cameroon, it is noticeable and no more news that students do engaged in series of unpleasant activities, which also invariably affects their academic achievement. What makes it a concern is the fact that such behavior could be injurious to the student himself/herself, his peers, friends, and schoolmates and even at home. Before any behavior can be termed as deviant behaviors, such behavior would have been extreme or deficit. Extreme behaviours in the sense that, such behaviours go beyond normal acceptable behaviours by the society. In another words, a behavior could be seen as deficit when a person lacks the required trait expected by the society. Students who are supposed to be in school are seen playing around, smoking Indian hemp and other social and emotional vices. In either ways, any behavior that does not conform to the general acceptable norm is either rejected or disowned. Among secondary school students, is often common to see them displaying one form of deviant or excess behaviours. This study is aimed at investigating the influence and the contributions of such deviant behaviors on the academic achievement of students. In an attempt to look deep into what constitutes deviant behaviors among secondary schools students; one needs to look at it from the universal point of view. some major features of any child with deviant behaviors which include inability to assimilate what is taught, inability to build or maintain satisfactory relationship with friends, classmates and teachers, display of abnormal behavior under a normal circumstance with apparent show of fear at home and school settings constitute indicators for this study.

\section{Background of the study}

Historically, in the Cameroonian educational system, children have suffered many times from psychosocial and handicapping conditions such as a lack of understanding and empathy from teachers, administrators and their peers. The literature is replete with evidence of such treatment leading to negative student behaviour and the resultant poor performance Angel (2015). Consistent with this, is the reality that the number of students with special needs or learning difficulties has been increasing rapidly. Of those children with special needs, however, the ones most likely to be misunderstood as those with deviant behaviors also known as emotional and behavioural disorders. This research calls into question the issue of what researchers consider normal behavior and deviant behaviors in schools. A discussion of the construct "deviant behaviors"/ "disruptive behaviours" within the purview of the Cameroonian educational system is provided in order to give credence and validity to this research.

Angel (2015) defined deviant behaviour as any behaviour that lacks conformity and acceptability of people in the society. Deviant behaviour describes an action or behaviour that significantly contravene from the accepted or prescribed norms of a given society. It is a deviation that attracts punishment or sanctions in the society or school. Diche (2016) posited that deviant behaviour is a behaviour that violates the laid down rules and regulations of a given organization or group. He also emphasize that deviant behaviour is a common phenomenon in the life of every human being but, stress that it is rampant among students in schools which has led them in joining secrets cults, and other heinous crimes in the school. Students with deviant behaviors commonly engage in behaviors (e.g., iverbal and physical aggression; social skills acquisition and performance deficits) that negatively influence both their ability to successfully negotiate peer and adult relationships and their educational experience (Cullinan and Sabornie 2004. This is largely due to their inability to adher to social and academic task, continuous negative peer pressure and poor interpersonal skills. Namely, when students are unable to negotiate social demands and meet teachers' expectations for school success (Lane. 2006), school becomes a formidable task. In the absence of effective interventions, these behavior patterns become more firmly established and less amenable to intervention efforts (Walker. 2004).

In recent years, increasing evidence (Cullina and Sabornie 2004; Walker. 1992; Walker. 2004) has established the negative academic outcomes typical of this population. For example, students with deviant behaviors earn lower grades, are less likely to pass classes, and experience higher rates of school dropout than typical students and students with other high incidence disabilities (Wagner and Cameto 2004). Despite increased attention to the academic needs of students with deviant behaviors, their academic achievement, like their behavioral and social skills, does not appear to be improving (Lane. 2002). 
Unfortunately, these poor outcomes do not improve when they leave the school setting. This group of students goes on to have negative employment outcomes, difficulties with substance abuse, and a high need for mental health services (Bullis and Yovanoff 2006; Walker. 2004). Given that between $2 \%$ and $20 \%$ of the school-age population is likely to have behavioural disorders, this is no small problem (Gresham. 2004; Landrum. 2003).

Prevalence rates for students with deviant behaviors who have comorbid academic and behavioral challenges vary, ranging from $25 \%$ to $97 \%$ (Reid. 2004). The poor academic functioning of students with deviant behaviors is not surprising given that academic underachievement is part of the identifying criteria in the definition for emotional disturbance (IDEIA 2004; Mooney. 2003). Although the comorbid existence of deviant behaviors and academic deficits has been documented over time (Nelson. 2004), in recent years, researchers have attempted to elucidate the specific characteristics of the academic performance of students with deviant behaviors (Alexander, Entwisle, \& Dauber, 1993; Barth, Dunlap, Dane, Lochman, \& Wells, 2004), suggest that students with deviant behaviors perform $1-2$ years below grade level, with significant differences in achievement as compared to students without disabilities (Kauffman 2001; Reid. 2004; Trout. 2003).

Accordingly, for a behavior to be identified as deviant behaviors, some traits have to be persistently visible over quite a period of time, such include: unacceptable or unguided behavior under normal circumstances, inability to maintain and build a lasting relationship, depression, aggression, retaliation and so on (DeRosier, Cillessen, Coie, \& Dodge, 1994). In addition, it should be noted that, any definition of deviant behaviors given, must emphasize that such traits displayed should be repetitive and persistent pattern of behaviours, which is visible over time and attested to in different circumstances. Emotional and behavioral disorders are manifested in the form of behavioral excesses or behavioral deficits. Behavioral excesses or externalizing behaviors are also referred to as under controlled behavior problems and are characterized by multiple instances of defiant, aggressive, disruptive, and noncompliant responses (Koth, Bradshaw, \& Leaf, 2008) . Almost threequarters of children with externalizing disorders pass through a predictable progression from less to more severe forms of social maladjustment. These behaviors seem to be the focus of teachers, who view them as intolerable as a result of the challenging of their authority, the interference of instruction, disruption of classroom routines, and adverse effect on classmates (Masi \& Favilla, 2000).

Behavioral deficits of deviant behaviors are referred to as internalizing behavior disorders or over controlled behaviors. These behaviors are characterized by inner-directed and covert actions. A child with internalizing deviant behaviors may be withdrawn, shy, depressed, and/or have dysthymia and other emotional or personality disorders. Just as externalizing disorders, these disorders are predictive of social adjustment difficulties and psychopathology (Masi \& Favilla, 2000). Internalizing behaviors often occur concomitant to impaired cognitive functioning, a lack of social competence and acceptance, language deficits, limited problem-solving strategies, and eventually result in nonattendance at school. Due to the nature of internalizing behaviors, they do not often come to the attention of teachers or other authorities. In cases where the problems are identified, they are overlooked because they are not seen as difficulties. This mistake of nonintervention must be avoided. If internalizing behaviors are not treated, the consequences carry the same seriousness as untreated externalizing behavior disorders (Koth, Bradshaw, \& Leaf, 2008).

Once students enter the school setting, their behaviors, interpersonal relations, and emotional adjustments contribute to their successful academic development. Positive school behaviors and interpersonal relations represent good adjustments in the school setting, whereas negative school behaviors and interpersonal relations represent poor school adjustments. Harrison, Vannest, Davis, and Reynolds (2012) found that the most common problem behaviors for children and adolescents, as reported by their teachers in general education classrooms in the United States, were categorized as externalizing, internalizing, and inattentive behaviors. Externalizing, internalizing, and inattentive behavioral problems have been linked to academic difficulties (Arnold, 1997; Masten et al., 2005). Therefore, it is important to further study these behaviors and how they affect the students' academic performance to better provide the students with more appropriate and effective interventions. 
Theoretically, students with deviant behaviors elicit rejection and tension from others such as teachers or same aged peers (Hankin, Stone \& Wright, 2010). When students behave in ways that are inconsistent with social expectations, teachers and peers may react negatively to those students. This creates a challenging environment for students, teachers, and peers. Not knowing how best to help those students, teachers may avoid spending time with them and may refer them elsewhere in the school, such as to a specialist or the principal. Similarly, peers may not know how to converse or interact with the problematic students, so the peers may also avoid contact with those students. Consequently, without additional support from the teachers and peers, the problematic students become isolated and less engaged, miss opportunities to experience successful relationships, and have fewer opportunities to learn from their teachers and peers (Arnold, 1997, Dobbs, \& Doctoroff, 2006). This pattern prevents an optimal learning environment and limits the efficacy of the teacher's classroom instruction. To effectively substantiate concepts and results emerging from this study, the study anchored on three psychological theories. These theories include the social learning theory by (Albert Bandura), Brunner's theory of instruction and Lev Vygotsky's socio-cultural theory of development. These theories aimed at guiding the researcher in understanding the concept of deviant behavior since it is a psychological concept. Both outlined theories clearly explain student's behavior within the school and society and the various psychological underpinning emerging from particular exhibited behavioural patterns. Learning theory is based on the principles of behavioural psychology, which hypotheses that a person's behaviour is learned and maintained by its consequences or rewards. Individual, thus learn deviant and criminal behaviour by observing other people and witnessing the rewards or consequences that their behaviour receives. For example, an individual who observes a friend shoplifting an item and not getting caught sees that the friend is not being punished for his/her actions and instead is rewarded by getting to keep the item he or she stole. That individual might be more likely to shoplift.

According to the cognitive development theory, criminal and deviant behaviours result from the way in which individuals organize their thoughts around morality and the law. During the first stage, called the preconventional stage which is reached during middle childhood, moral reasoning is based on obedience and avoiding punishment. The second level is called conventional level and is reached at the end of middle childhood. During this stage, moral reasoning is based on the expectations that the child's family and significant others have for him or her. The third level of moral reasoning, the post conventional level, is reached during early adulthood at which point individuals are able to go beyond social conventions. That is, they value the social system. People who do not progress through these stages may become struck in their moral development and as a result become deviants or criminals. Additionally, all humans have criminal tendencies. These tendencies are curbed, however, through the process of socialization. A child that is improperly socialized and guided then could develop a personality disorder that causes him or her to direct antisocial impulses inward or outward. Those who direct them inward become neurotic while those that direct them outward become deviant or criminal (Wagner and Cameto 2004).

Contextually, be it deviant behaviors, disruptive behaviours, or emotional and Behavioral Disorders strongly affect the academic performance of children who suffer from the behavioural inconsistencies. This is because early adolescents with deviant behaviors are often regarded as more difficult students to teach than students with other kinds of problems and are more likely to be (a) under identified, (b) recommended for exclusion from general education settings and (c) found to attain marginal or unsatisfactory educational outcomes. Of all students in disability categories, students with deviant behaviors have the lowest grade-point averages (Alexander \& Olson, 2005). Almost one-half of students characterized as deviant behaviors have poor academic achievement and have failed at least one subject/course in the most recent school year. A majority of deviant behaviors students fail their yearly promotion examinations. Perhaps contributing to the low achievement level is the rate of absenteeism, which is higher than students of any other disability, at an average of 18 days (yearly) (Petras, Masyn, Buckley, Ialongo, \& Kellam, 2011).

The Challenge of deviant behaviors is enormous. Children with deviant behaviors exhibit behaviors that make the process of education quite difficult. The majority of these children enter schools devoid of the skills, interpersonal behavior, and attitudes necessary to satisfactorily participate in the classroom process 
(Sutherland, 2001). Social skill deficits include peer relationship problems, aggression, and oppositionality (Sutherland 2002). Other social problems, which are often associated with language problems, include withdrawal, depression, and antisocial behavior (Hendrickson 1998). The combination of social and academic difficulty results in classroom problems such as disruptive and off-task behavior, which affect not only the deviant behaviors student, but other students and the teacher as well (Sutherland 2002).

Each teacher in the school system should have enough knowledge of the disorder and how to work with deviant behaviors and to give children who suffer from deviant behaviors the same chance for success that other students have. Students with deviant behaviors can be taught effectively, even in the general education setting. Research is beginning to provide possible methods of prevention and intervention for these children. With the proper application of these methods, children with deviant behaviors have a greater possibility of successfully completing high school and participating in a successful life beyond high school (Lane, Gresham, \& O'Shaughnessy, 2002; Sutherland, 2001). It is the responsibility of Implications of deviant behaviors for educators to make sure they are prepared to deal with the implications of Behavioral Disorders for the processes of the classroom.

As the field of educational psychology continues to evolve and the new knowledge we acquire is internalized, the need for education of children with emotional and deviant behaviors should be apparent to every stakeholder within the Cameroonian educational system. Specifically, it is paramount that classroom teachers become more equipped in their approach to teaching. The effective classroom teacher should endeavour to acquire the necessary skills in an effort to maximize the potential of our students with deviant behaviors and disruptive behaviours. In achieving these objectives, the need for a greater understanding of students with deviant behaviors cannot be over-stated. This research seeks to help teachers understand and work with students impacted by deviant behaviors. It draws on the researcher's own experience as an educational psychologist as well as discussions with both probationary and experienced teachers and is intended to guide educators on how to deal with students who display symptoms of deviant behaviors.
The imperativeness of guidance and counseling services on students' behavior modification in both urban and rural secondary schools in the South West Region of Cameroon cannot be over emphasized. Collins (2002) says that guidance and counseling is important because it provides an insight on working knowledge, skills and attitudes. It is necessary to assist young people to be disciplined and be able to deal with challenges and realities they face in their ever changing environment, understand themselves, their academic social and physical environment, realize their potentials, as well as identify opportunities in a world where chances for further training, employment and advancement continue to dwindle. Learners are counseled to alter any maladjusted behaviour. Since most citizens are involved in education process directly or indirectly, the impact of guidance and counseling is real to them.School aged children spend most of their time away from home in Educational institutions .It is hoped that, at the very least, they should experience healthy classroom environments conducive to the ultimate goal of creating the new and brighter generation. Alas this seems like a "pipe dream" for many. Historically, in the Cameroonian educational system, children have many times suffered from psycho-social and handicapping conditions such as a lack of understanding and empathy from teachers, administrators and their peers. In his analysis of the Cameroonian educational system, Tambo (2005) opined that, "schools in Cameroon provide a solace where children escape the realities of the home and community from which they come. These harsh realities have made for a devastating impression on the psyche of the students which may explain the social deviance and low performance of pupils". Consistent with this perception, the number of students with deviant behaviors has been observed to be increasing rapidly. Of those students, however, the ones most likely to be misunderstood are those with deviant behaviors and disruptive behaviours.

\section{Statement of the Problem}

deviant behaviors poses serious concern not just to teachers but also to parents, students and other stakeholders involved in the educational process especially as such behaviours tremendously affect the academic performance of such students in class. In Limbe sub-division where this study is conducted, another disturbing fact observed is that, students displaying tenets of deviant behavior do not see such 
acts as abnormal, in fact, in most cases, they are not bothered by it because they perceived it as normalcy. The implication of such phenomenon is persistent, stealing, fighting, bullying, social withdrawal, stealing, cheating etc that, continue and is detriment to such students and people around him/her. It was equally observed that, students that demonstrate deviant behaviors do often encountered challenges in school and outside school when compared with their mates, they are likely to have lower scores, exhibition of truancy, lack concentration and prone to drop out. Therefore, because of the severity and frequency of these behaviours students with deviant behaviors are less heard, occasionally listened to, less valued and less respected. It was also observed by the researcher that emotionally disturbed students do display irrational behaviours that consequently affect their academics and self-confidence. Students showing deviant behavioral tendencies are most likely to develop unaccepted relationship at home and school vicinity. It was thus based on the above observations that this study seeks to find out the relationship between deviant behaviors and the academic achievement of early adolescents within the Limbe I municipality.

\section{RESEARCH OBJECTIVES}

\section{General Research Objective}

The current study examined the influence of deviant behaviors on the academic participation of early adolescents.

\section{Specific Research Objectives}

1) To ascertain how bullying influence the academic participation of early adolescents with deviant behaviors.

2) To assess how social withdrawal stimuluses the academic participation of early adolescents with deviant behaviors

3) To determine how classroom aggression influences the academic participation of early adolescents with deviant behavioral patterns.

\section{RESEARCH QUESTIONS}

\section{General Research Question}

Do deviant behaviors influence the academic participation of early adolescents?

\section{Specific Research Questions}

1) To what extent does classroom bullying influence the academic participation of early adolescents with deviant behavioral patterns?

2) How does social withdrawal influence academic participation of early adolescents with deviant behavioral patterns?

3) How does classroom aggression influence the academic participation of early adolescents with deviant behavioral patterns?

\section{REVIEW OF RELATED LITERATURE}

The social understanding of the study of deviant behaviours examined cultural norms; how they change over time, how they are enforced, and what happens to individuals and societies when norms are broken. Deviance and social norms vary among societies, communities, and times, and often sociologists are interested in why these differences exist and how these differences impact the individuals and groups in those areas. What is deviant to one group may not be considered deviant to another. Sociologists define deviance as behaviour that is recognized as violating expected rules and norms. It is simply more than nonconformity, however; it is behaviour that departs significantly from social expectations. Sociologists stress social context, deviance is looked at in terms of group processes, definitions, and judgments and not just as unusual individual acts. This section explores three vital aspect, theoretical perspectives and the empirical review supporting the current research.

\section{CONCEPTUAL REVIEW}

\section{The Concept of Deviant Behaviour}

Deviance simply means to go astrayll. In sociology, social deviance or deviance means those behaviours or characteristics that violate significant social norms and expectations and are negatively valued by a large number of people. We can also look at deviance simply as those behaviours that breach commonly held norms, values and expectations of a society. To that, those that depart from conventional norms are called deviants. Haward Becker, a renowned sociologist, sees deviance as that behaviour that people so label. The study of deviance can be divided into the study of why people violate laws or norms and the study of how society reacts. This reaction includes the labeling process by which deviance comes to be recognized as such. The societal reaction to deviant behavior suggests that social groups actually create deviance by making the rules whose 
infraction constitutes deviance and by applying those rules to particular people and labeling them as outsiders (2). We are interested in studying deviance in order to understand why people violet social norms; i.e., why do some people commit crime while others conform to norms? We are also interested in knowing how deviant behaviour mentally affects the well-being of an individual and the society at large. Finally, is to suggest psychological techniques in providing psychotherapy to deviant behaviours.

Some types and examples of deviant behaviours in many societies include: bullying, armed robbery, examination mal-practice, rape, forgery, drug abuse and addiction (smoking and drinking), bribery and corruption, vandalization, gangsterism, intimidating behaviours, keeping late hours, sexual harassment and indecent dressing (such as transparent and tied cloths for girls, and radical wears or appearance like coiling of hairs etc for boys), disobedience to parents, elders, and other social authorities, addicted to party, gossiping, greed, jealousy, truancy, among others. It should be noted that all sociologists and social workers have subscribe to the position that there is nothing inherently criminal in a particular act which makes such act deviant. They are only so because they are prescribed by the society. Deviance is therefore relative and not absolute. An act is only deviant when it is socially defined as such. Definition of deviance differs from time to time, place to place and from group to group. For example, to kill a fellow human being is a deviant act but to kill an enemy soldier in times of war is a norm. Behaviour that may be considered deviant in one culture may not be in another. In addition to that, when an Oba fell short of expectations of his people in pre-colonial Yoruba society, he was presented with a calabash which symbolizes that his people have lost confidence in him. He was therefore forced to commit suicide. In other cultures, this is not the case. This suggests the positivism and negativism of deviance.

\section{Effects of Deviant Behaviour}

The following are the effects of deviant behaviour:

$>$ It affects teaching and learning as teachers spend more time trying to control students rather than teaching them.

$>$ Most involved students don't benefit from schooling It affects their academic performance because they are often into one deviant act or the other losing most vital class lessons.
It leads to poor parent: Child relationship as most reasonable parent's withdraw their love and care on deviant children and also most deviant children don't like coming closer to their parents because of fear of being hint.

$>$ Deviant students often threaten their teachers, school authorities and even parents at home.

It leads to demonstrations and destruction of school properties and in some cases deviant students observe frequent demonstrations in the face of little issues.

\section{Types of Deviant Behaviour in our School System}

Ibuchim (2016) identified the following as types of deviant behaviour in our educational system.

Examination Malpractice: It is an unholy or barbaric act perpetrated by the students, examines and other agents during and after examination with intention to have undue advantage and earn unmerited grade. Most students in our school at various levels indulge or delve into malpractice which is against the examination act of 1999 which prescribed rules and sanctions but, yet students also continue to live by it. The poor performance of students nationwide was as a result of examination malpractice in our schools.

* Bullying: It is an aggressive behaviour and is a behaviour intended to hurt (Paschal, 2015). Bigger, stronger students always lord it over the smaller or tender ones. Okechukwu (2016) enumerated various forms of bullying such as physical assault, extortion and verbal humiliation etc. Most students involves in bullying each other in our school with the intention of subduing them physically.

* Truancy: This means being away from home and school during school hours. This habit makes students to spend their time in inappropriate places which could lead to drug abuse in male and unwanted pregnancy in female. Dike (2015) explain that, this involves leaving the school premises and coming back any time without permission and also running away from school after resumption. If adolescents are not gainfully occupied in the school or at home, they develop lazy tendencies and may become truants. Truancy in the students shows up in many ways the students nominal role is very low (Amaka \& Joy, 2015).

* Stealing: This involves stealing fellow student's or school properties. Kingsley (2015) explained 
that most students indulge in the habit of taking what does not belong to them in school. This behaviour if not checked could give rise to other abnormal behaviours in a student and affects their academic performance.

Lateness to school: Pere (2014) explained that there is prescribed time for resumption of school but some students often come to school late when morning assembly is over and in some cases, when the teacher is already in the class teaching. This leads to distraction.

- Cultism: This occurs when group of students come together under one name with bad intention of intimidating fellow students to join them or disturbing the activities of the school for their evil objective (Chima, 2015). According to him most students involves in cultism to compensate their academic inadequacy. It is a major misbehavior and the after effects of their activities do know one any good.

* Drug Abuse: This means indiscriminate use of drugs without doctor's prescription or use of drugs other than their purpose. Chamberlin (2015) posited that students in school and adults outside the school sitting have been found smoking, Indian hemp, heroine, cigarette and other drugs not prescribed by doctors to feel "high""shine their eyes, to commit various dangerous crimes or to feel bold to talk with their teachers or the opposite sex.

* Sex offences: This involves various degree of sexual misconduct exhibited by students which include masturbation, lesbianism, homosexual, premarital sex, abortion. This affects their academic performance or lead to school dropout.

* Absenteeism: Staying away from school for no reason or without permission. Most students absent themselves from school without the permission of the school authority and this affect their performance in school.

\section{Externalizing Behaviors and Academic Performance}

Previous studies have linked externalizing behaviors with later academic development; however, the longterm effects have not always been consistent. Generally, students with externalizing behavioral problems were more likely to have academic difficulties in school. Similar negative effects of externalizing behavioral problems on academic performance have been found among students in early elementary school years (i.e., preschool, kindergarten, and first grade students; Arnold, 1997; Henricsson \& Rydell, 2004; Miles \& Stipek, 2006) and among students in later elementary school years to middle school years (i.e., fourth through eighth grade students; Masten et al., 2005; Obradovic et al., 2010).

The concurrent and long-term effects of externalizing behavioral problems on academic performance have been examined in the literature. Although the concurrent effects of externalizing behavioral problems have been consistent, the long-term effects have not been as stable. Concurrent results indicated that students with externalizing behavioral problems constantly had more academic problems during the same school year (Arnold, 1997; Miles \& Stipek, 2006). Nevertheless, longitudinal results have varied. For example, three longitudinal studies indicated that students with externalizing behavioral problems had poorer academic performance two years later (Henricsson \& Rydell, 2004) and seven years later (Masten et al., 2005; Obradovic et al., 2010). Conversely, three other longitudinal studies indicated that students with externalizing behavioral problems did not have academic difficulties two years later, four years later (Miles \& Stipek, 2006), five years later (Caprara et al., 2000), and ten years later (Masten et al., 2005). Variation in findings may have been attributed to a variety of ways the researchers defined externalizing behaviors, how they defined academic performance, or the differential effects of the context. For instance, while Miles and Stipek (2006) determined the students' academic performance by measuring their literacy skills, Masten et al. (2005) determined the students' academic performance by obtaining their grade point averages and parent, teacher, and self reports.

\section{Internalizing Behaviors and Academic Participation}

Prior studies have strong evidence indicating significant relationships between internalizing behaviors and academic success. More specifically, students with internalizing behavioral problems were more likely to exhibit academic struggles in school. Consistent negative effects of internalizing behavioral problems on academic performance were found across different grade levels. For instance, internalizing behavioral problems significantly predicted more learning problems and lower reading performance among preschool students (Massetti et al., 2008), 
kindergarten through first grade students (Horn \& Packard, 1985), and second through ninth grade students (Rapport et al., 2001).

Furthermore, researchers have reported consistent negative effects of internalizing behavioral problems among concurrent and longitudinal studies. For example, students with internalizing behavioral problems had lower reading performance, poorer classroom performance, and lower scholastic performance scores during the same school year (Horn \& Packard, 1985), one year later (Horn \& Packard, 1985), two years later (Bub et al. (2007), three to four years later (Rapport et al., 2001), and eight years later (Massetti et al., 2008).

\section{THEORETICAL REVIEW}

\section{Social Learning Theory}

Social learning is a general theory that offers an explanation of the acquisition, maintenance, and change in criminal and deviant behavior that embraces social, nonsocial, and cultural factors operating both to motivate and control criminal behavior and both to promote and undermine conformity. The basic proposition is that the same learning process in a context of social structure, interaction, and situation, produces both conforming and deviant behavior. That is, the theory is not, contrary to the misconception sometimes found in the literature, simply a theory of the acquisition of novel behavior, a theory of bad companions, or a "cultural deviance" theory. It is not solely a "positivistic" theory of the causes of crime, addressing only "why they do it," and incapable of explaining "why they do not" (Gottfredson and Hirschi, 1990; see Akers, 1996; 1998). Rather, the theory incorporates crime facilitating as well as protective and preventive factors. The probability of criminal or conforming behavior is a function of the balance of these influences on behavior not only those operative in one's learning history, but also on those operating at a given time in a given situation, and those predictive of future behavior (Akers, 1998:59).

Differential association refers to direct association and interaction with others who engage in certain kinds of behavior or express norms, values, and attitudes supportive of such behavior, as well as the indirect association and identification with more distant reference groups. The groups with which one is in differential association provide the major immediate and intermediate social contexts in which all the mechanisms of social learning operate. The most important of these groups are the primary ones of family and friends, but the concept of differential association also includes both direct and indirect interaction and exposure to secondary and reference groups as well as mass media, internet, computer games, and other "virtual groups" (Warr, 2002). Those associations that occur earlier (priority), last longer and occupy more of one's time (duration), take place most often (frequency), and involve others with whom one has the more important or closer relationship (intensity) will have the greater effect on behavior. The theory hypothesizes that the more one's patterns of differential association are balanced in the direction of greater exposure to deviant behavior and attitudes, the greater the probability of that person engaging in deviant or criminal behavior.

Differential Reinforcement. Differential reinforcement refers to the balance of anticipated or actual rewards and punishments that follow or are consequences of behavior. Whether individuals will refrain from or commit a crime at any given time (and whether they will continue or desist from doing so in the future) depends on the balance of past, present, and anticipated future rewards and punishments for their actions. The greater the value, frequency, and probability of reward for deviant behavior (balanced against the punishing consequences and rewards/punishment for alternative behavior), the greater the likelihood that it will occur and be repeated. Reinforces and punishers can be nonsocial; for example, the direct physical effects of drugs and alcohol. However, the theory proposes that most of the learning in criminal and deviant behavior is the result of direct and indirect social interaction in which the words, responses, presence, and behavior of other persons directly reinforce behavior, provide the setting for reinforcement (discriminative stimuli), or serve as the conduit through which other social rewards and punishers are delivered or made available. The concept of social reinforcement (and punishment) includes the whole range of actual and anticipated, tangible and intangible, material and symbolic rewards valued in society or subgroups. Social rewards can be highly symbolic. In selfreinforcement the individual exercises self-control, reinforcing or punishing one's own behavior by taking the role of others, even when alone. The balance of reinforcement may motivate individuals to commit 
law violations or deviant acts even in the face of their own definitions unfavorable to those acts, but the acts are most probable when both the reinforcement balance and the balance of one's own definitions are in the same deviant direction.

Imitation refers to the engagement in behavior after the direct or indirect (e.g. in media depictions) observation of similar behavior by others. Whether or not the behavior modeled by others will be imitated is affected by the characteristics of the models, the behavior observed, and the observed consequences of the behavior (vicarious reinforcement) (Bandura, 1977). The observation of salient models in primary groups and in the media affects both pro-social and deviant behavior (Donnerstein and Linz, 1995). Imitation is more important in the initial acquisition and performance of novel behavior than in the maintenance or cessation of behavioral patterns once established, but it continues to have some effect in maintaining behavior.

These social learning concepts define sets of variables that are all part of the same underlying process that is operative in each individual's learning history (both learning from and influencing others), in the immediate situation in which an opportunity for a crime occurs, and in the larger social structural context ( at both the meso-level and macro-level). The social learning process is dynamic and includes reciprocal and feedback effects. Reinforcement in operant conditioning is a response-stimulus-response process in which behavior produces consequences that in turn produce the probability of the behavior being repeated (Skinner, 1959). Therefore, contrary to the way some have characterized the theory (Thornberry, et al. 1994), reciprocal and sequential effects of social learning variables and deviant/conforming behavior are recognized, albeit, with an emphasis the effects of the learning variables on deviant behavior. The typical temporal sequence in the process by which persons come to the point of violating the law or engaging in other deviant acts is hypothesized to be one in which the balance of learned definitions, imitation of criminal or deviant models, and the anticipated balance of reinforcement produces the initial delinquent or deviant act. The facilitative effects of these variables continue in the repetition of acts, although imitation becomes less important than it was in the first commission of the act. After onset or initiation, the actual social and non-social reinforcers and punishers affect whether or not the acts will be repeated and at what level of frequency. Both the behavior and the definitions favorable and unfavorable, are affected by the consequences of the initial acts. Whether a deviant act will be repeated in a situation that presents, or is perceived to present, the opportunity depends on the learning history of the individual and the set of definitions, discriminative stimuli and reinforcement contingencies in that situation.

\section{Social constructivism: Lev Vygotsky (1896-1934)}

Vygotsky's model of constructivism is "social" constructivism that illustrates the interaction between social and practical elements in learning through speech and practical activities (Vygotsky 1978). By this model the learner functions at two levels; firstly as s/he constructs meaning through practical activity at an intrapersonal level and secondly as $\mathrm{s} / \mathrm{he}$ interacts with others using speech and cultural tools to connect the meaning of the interpersonal world $s /$ he shares with others. The model advocates collaborative learning with peers and other adults. The social constructivist model emphasizes the importance of the relationship between student/pupils and teachers in learning processes.

The teacher's role is of special significance in Vygotsky's Zone of Proximal Development (ZPD), which is the centerpiece of the theory. The ZPD refers to the difference between what a child can achieve unaided in problem solving and what $\mathrm{s} /$ he can achieve with the help of adults/ teachers or peer mentors. Vygotsky therefore sees the child as an apprentice who acquires knowledge and skills through help from those who already possess such knowledge and skills using scaffolding. Scaffolding is pedagogical techniques, for example, questioning, illustrations, etc., that can enable the learner to learn better. However, the capacity to learn is based on the more competent person's didactic role. In Africa, peer mentors are quite useful in children's learning in the ZPD.

Vygotsky does not advocate procedural learning but more intellectual development through collaborative learning and cooperative learning in group work and project. These are valuable at all levels of the school system. The development of language and the articulation of ideas are central to learning. The role of the teacher and peers is to enter into dialogue with the learner to enable understanding of meaning and help the learner to refine such understanding with the 
use of language. The major premise of Vygotsky's theory is the role of social interaction in cognitive learning. Human memory is central to learning.

\section{EMPIRICAL REVIEW}

\section{Bullying Influence the Academic participant of Early Adolescents with Deviant Behaviors}

Many researchers have examined the development of childhood externalizing behavior and subsequent school performance (2000; Henricsson \& Rydell, 2004, Obradovic et al., 2010). For example, Miles and Stipek examined the association between aggressive behaviors and academic performance among a sample of kindergarten and first grade students; both shortterm (same year) and long-term (two and four years later) associations were examined. Concurrent correlation results revealed that students with high levels of aggression, as reported by their teachers, were more likely to exhibit literacy difficulties that same year. Nevertheless, long-term results from their path analyses revealed that aggressive students in first grade did not exhibit literacy difficulties in third grade, and aggressive students in third grade did not exhibit literacy difficulties in fifth grade. As a result of the path analysis method that was utilized examined the data, they accounted for the student's prior academic performance and prior behavioral problems. Once the student's prior academic performance and prior behaviors were controlled for, the student's behavioral problems no longer significantly predicted later academic performance.

Masten (2005) and Obradovic (2010) examined the longitudinal relationship between externalizing behavior and academic performance over multiple assessments spanning 20 years. At the start of the study, the students were 8 to 12 years old $(N=205)$. The students were reexamined three times later: Time 1, 7 years later while they were about 17 years old; Time 2, 10 years later while they were about 20 years old; and Time 3, 20 years later while they were about 30 years old. The authors used a series of nested cascade models through structural equation modeling to test the developmental progressive effects of externalizing problems in childhood. Based on their developmental theory and longitudinal data, Obradovic et al. described cascade models as the examination of "problems in one domain spreading to affect later development through various pathways" Masten and Obradovic. found that students who had externalizing problems during the elementary school years had reduced academic competence seven years later (about 17 years old) as measured by the students' grade point averages and parent and self-report of academic status. In turn, students who displayed academic underachievement while they were 20 years old had significantly more internalizing problems when they were 30 years old. Nevertheless, other long-term effects of externalizing behaviors were not revealed (Masten et al., 2005); the authors found that students who had externalizing behaviors when they were 17 or 20 years old did not have significantly lower academic competency when they were 30 years old.

\section{Classroom Aggression Influences The Academic} participants Of Early Adolescents With Deviant Behavioral Patterns.

Cole, Martin, and Powers (1997) posit that the association between internalizing behaviors and academic performance is a reciprocal causal process. For instance, when the low performing students are identified by the teacher and peers as a struggling student (i.e., negatively perceived), the student's internalizing symptoms such as self-perceived incompetence, insecurities, and worrying thoughts are heightened. This leads the student to be even more distracted from the academic content and become more worried about how others negatively perceive them. This reciprocal process indicates that students with internalizing behaviors will produce many academic difficulties.

The negative effects of internalizing behavioral problems on academic performance were also found in a study that examined both the short- and longterm effects among a sample of 325 students in elementary school (Rapport et al., 2001). At the start of the study, Rapport et al. obtained the students' intelligence (i.e., measured by two subtests from the Kaufman Brief Intelligence Test, K-BIT), internalizing behavior (i.e., teacher reported on the students' anxiety/depression and social withdrawal), classroom performance (i.e., teacher reported on the students' academic success and productivity), and cognitive function (i.e., their performance on the vigilance/continuous test and short-term memory test). The students were then monitored for the next three to four years when the authors obtained the students' academic performance in three areas (i.e., reading, math, and language). The authors used structural equation modeling to examine the 
concurrent and longitudinal effects of internalizing behaviors.

They found that socially withdrawn behaviors were directly associated with classroom performance, but not directly with cognitive functioning or with later scholastic performance; however, socially withdrawn behaviors were indirectly associated with later scholastic performance. Therefore, the results imply that socially withdrawn behaviors indirectly affect later scholastic performance via classroom performance. Conversely, the authors found that anxious/depressive behaviors were directly associated with cognitive functioning but not directly with classroom performance or later scholastic performance; however, anxious/depressive behaviors were indirectly associated with later scholastic performance. Hence, the results imply that anxious/depressive behaviors indirectly affect later scholastic performance via cognitive functioning.

\section{Social Withdrawal Influences The Academic participants Of Early Adolescents With Deviant Behaviors}

In a longitudinal study of over 14 years, McLeod and Kaiser (2004) explored the effects of early childhood externalizing and internalizing behavioral problems on educational attainment in adulthood. They assessed students' externalizing and internalizing problems according to parents' reports at ages 6 through 8 . These students' educational attainment was then monitored for the next 14 years.First, they examined the effects of externalizing and internalizing behaviors on educational level separately. When no background controls were included in the models, the authors found that students who had high internalizing and externalizing problems were significantly less likely to graduate from high school; however, only externalizing problems significantly predicted lower college enrollment. When all of the background controls were included in the models (i.e., student's race, sex, birth weight, and age, and mother's delinquency, academic aptitude, self-esteem, age at time of birth, education level, marital status, and poverty duration), similar results were found.

Next, to examine the effects of externalizing and internalizing behaviors together on high school degree receipt, hierarchical regression analyses were conducted. When no background controls were included in the models, externalizing problems significantly predicted high school degree receipt beyond internalizing problems; however, internalizing problems did not predict high school degree receipt beyond externalizing problems. Similar results were reported when all of the background controls were included in the models. Finally, similar analyses were conducted to examine the effects of externalizing and internalizing behaviors together on college enrollment. When no background controls were included in the models, externalizing problems significantly predicted college enrollment beyond internalizing problems; however, internalizing problems did not predict college enrollment beyond externalizing problems. When all of the background controls were included in the models, neither externalizing nor internalizing problems significantly predicted college enrollment. Based on their findings, the authors surmised that even though both internalizing and externalizing behaviors predicted later educational attainment, externalizing behaviors were more influential and continued to affect educational attainment long after high school.

Overall, research on the effects of multiple behavioral problems on the students' academic performance using the uncombined approach produced varied results. For instance, only inattentive behaviors predicted academic performance in the same year (Barriga et al., 2002) and five years later net of externalizing and internalizing behaviors (Duncan et al., 2007). Conversely, externalizing and internalizing behaviors predicted academic performance three years later net of inattentive behaviors (Farmer \& Bierman, 2002). Similarly, externalizing and internalizing behaviors predicted later school drop-out after controlling for behavioral problems in one sample; however, results were not the same in the second sample (Janosz et al., 1997). More inconsistent results were found; externalizing behaviors significantly predicted later high school degree receipt after controlling for internalizing behaviors, but internalizing behaviors did not predict later high school receipt after controlling for externalizing behaviors. Furthermore, neither externalizing nor internalizing behaviors predicted later college enrollment after controlling for other behavioral problems (McLeod \& Kaiser, 2004).

\section{RESEARCH METHODOLOGY}

\section{Research Design}

The design used for this study was the survey research design. The surveyresearch design is a design in 
which a group of people or items are studied by collecting and analysing data through the use of a questionnaire and/or an interview schedule from a few people or items. The main advantage of the survey design is its ability to produce large amounts of valuable data within a short space of time. In other words, it is economical. The choice for this design was appropriate because it enabled the researcher to collect in-depth information concerning how deviant behaviour influence the academic achievement of early adolescents in the selected primary schools. The respondents were then observed and the information gathered was compared to the pre-existing theory. Qualitative methods provided the otherwise relatively non-existent data on the characteristics of deviant behaviours in the schools selected in terms of bullying, aggression and social withdrawn.An interview which is a qualitative method of data collection was used to collect qualitative data. We chose a qualitative approach for this study for several compelling reasons. In general, qualitative research methods are especially useful in discovering the meaning that people give to events they experience (Bogdan \& Biklen, 2003). The purpose of this study was to discover the meaning that administrators give to the collection, analysis and use of behavior data to improve student success in school and in society.

\section{Population of the study}

The target population comprised of all students with deviant behaviours in the selected schools. This study selected 32 students with deviant behaviours from a total population of 1,105 students present in the selected schools at the time this research was conducted.

\section{Sampling Technique and Sample Size}

The Purposive sampling technique was used to select the entire 32 students with deviant behaviours as key respondents. The target population was so small that selecting a sample would be meaningless and that taking the whole population in such cases was advisable. In addition, class lecturers were sampled randomly from those selected schools that offered the opportunities the students were pursuing based on their teaching subjects besides teaching in the extra classes attended by students with deviant behaviours.

\section{Validity and Reliability of instruments}

Validity indicates the degree to which an instrument measures what it is supposed to measure (Kothari, 2004). It's a non-statistical method, notes Orodho (2004), used in validating the content applied in research tools such as questionnaire and structured interviews. In the pilot study that was carried out, appropriateness of language used in the questionnaire and interview guides was checked, after which appropriate modification of the tools was made to suit the respondent. The developed questionnaires were administered to a few subjects who were not participant in the real study. From the two parts of the instruments correlation coefficient was determined. Ambiguous questions were removed as moderation and introduction of new items were done.

\section{Data Collection Procedure}

At the beginning of the data collection exercise, the researcher had booked an appointment with school teachers, students for interviews using interview schedules. The interviews elicited an in- depth information through probing the respondent. Identified students with deviant behaviours and the school teachers were issued with the questionnaires which were collected by the researcher after two weeks. Only teacher's participated in the interview process. Chis was aimed at complementing the responses gotten from students questionnaire.

\section{Data Analysis}

The process of data analysis involved both qualitative and quantitative methods, observe Mugenda and Mugenda (1999); it is from the results of such analysis that the researcher is able to make sense of the data. The process of data analysis started during fieldwork. To collect data from the respondents, the field notes were utilized. At the end of each day, data were triangulated in order to draw up the relationship. The data were analyzed qualitatively. Observation data were analyzed thematically. Data from the structured interview were converted into a write up using pre-determined coding categories and reported in narrative form. Field notes was interpreted each day and emergent themes identified. After interpretation, data were fitted into the various themes, guided by the research objectives and questions. The questionnaires yielded qualitative data. Interviews yielded qualitative data. The data was analyzed and tabulated using descriptive statistics such as sample tables, pie charts, bar graphs, 
frequencies and percentages. These were chosen because they communicate the findings to the majority of the readers. This mode of presentation is given a quick visual impression of the quantifiable variables affecting the orientation of students with deviant behaviours. The researcher assembled all the questionnaires and the interview schedule obtained from the field. The instruments were then serialized numerically. The data were presented with the aid of frequency tables, pie charts and percentages. Qualitative data were analyzed narratively and descriptively based on the study objectives. From the mentioned form of data presentation, major findings of the study and discussions were made on the basis of the study, and then the researcher gave the conclusion and the recommendations.

\section{PRESENTATION OF FINDINGS}

\section{Section A: Socio-demographic characteristics of respondents}

Analyses were conducted to determine whether any demographic variables (gender and chronological age) had any significant influence to the study or should be recommended for use as control variables in subsequent analyses. This was because principle analyses involved correlations between deviant/problem behavior and academic achievement, potential demographic confounds (any demographic variables that might be associated simultaneously with problem behaviors and academic achievement) were investigated. From the information obtained, 33.3 percent of the respondents were females and 66.7 percent were males. This enhances the understanding of the number of students with deviant/problem behavior for which this study was designed. It is vivid that a majority of the respondents occupy the age group $09-14$, followed by the age group 15-18. This is a sensitive and crucial developmental age which needs a lot of parental guidance. Early Adolescents have no stable personality due to developmental changes which announces this developmental stage. Thus the relevance of respondent's age group is of paramount importance.

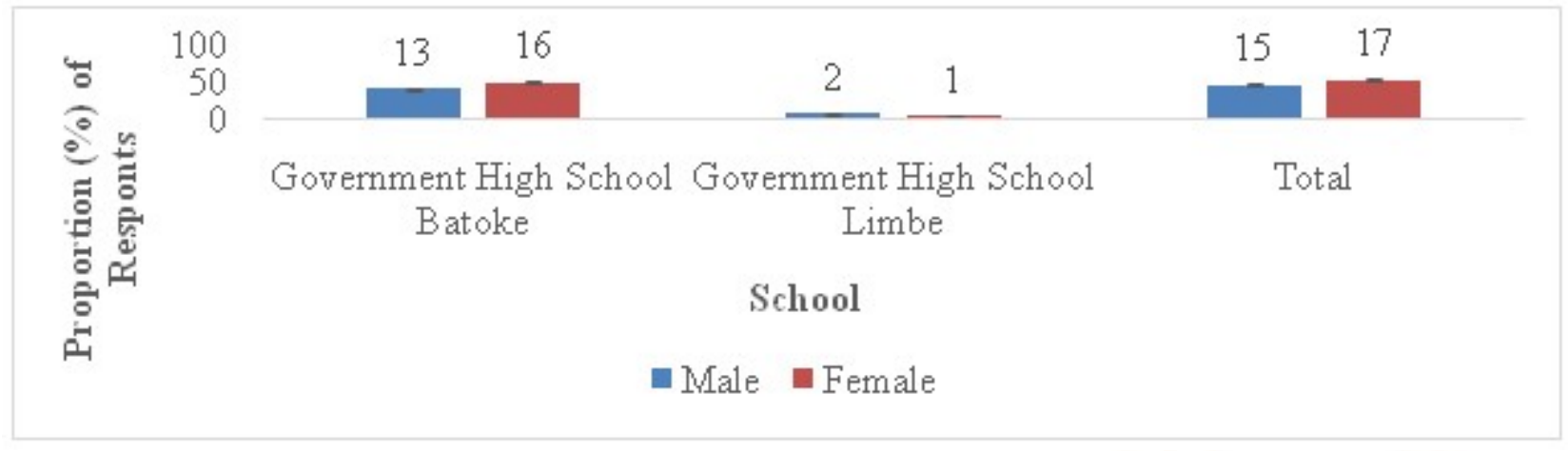

Figure. 4.0. Respondents Gender and Percentages 
International Journal of Trend in Scientific Research and Development (IJTSRD) ISSN: 2456-6470

Section B: Table 4.1, deviant behaviour on Academicparticipation of Students (Aggression, Bullying and Withdrawal)

\begin{tabular}{|c|c|c|c|c|c|c|c|}
\hline Aggression Scale & $\mathbf{N}$ & ST & QO & VO & $\bar{x}$ & Std Dev & Dec. \\
\hline Defies teachers or other school personnel & 02 & 09 & 11 & 10 & 2.6970 & .91095 & A \\
\hline Argues or quarrels with others & 11 & 10 & 09 & 02 & 2.2879 & .92429 & $\mathrm{R}$ \\
\hline Teases or taunts others & 04 & 06 & 10 & 12 & 2.7879 & .95297 & A \\
\hline Takes others property without permission & 04 & 06 & 10 & 12 & 3.0606 & .82048 & A \\
\hline Is physically aggressive or fights with others & 14 & 09 & 11 & 00 & 2.2879 & 1.04903 & $\mathrm{R}$ \\
\hline Gossips or spreads rumours & 02 & 08 & 13 & 09 & 2.0758 & .84691 & $\mathrm{R}$ \\
\hline Is disruptive & 04 & 06 & 10 & 12 & 2.8939 & 1.03966 & A \\
\hline Breaks rules & 00 & 15 & 02 & 15 & 1.3333 & .70892 & $\mathrm{R}$ \\
\hline I slap or kick peers at the slightest mis & 04 & 11 & 04 & 14 & 1.5909 & .67885 & $\mathrm{R}$ \\
\hline I call other kids bad names. & 04 & 06 & 10 & 12 & 3.2121 & .66830 & $\mathrm{~A}$ \\
\hline I threaten to hurt or to hit peers & 11 & 10 & 01 & 10 & 1.6061 & .55133 & $\mathrm{R}$ \\
\hline Mean score & 560 & 96 & 91 & 108 & 2.18484 & 0.693022 & $\mathbf{R}$ \\
\hline \multicolumn{5}{|c|}{$\begin{array}{l}\text { Table 4.2, Bullying scale (Never (N), Sometimes (ST), Quite Often (QO) } \\
\text { scale }\end{array}$} & \multicolumn{3}{|c|}{ Very Often (VO) Bullying } \\
\hline I upset other pupil for the fun of it. & 02 & 12 & 11 & 07 & 1.8182 & .76277 & $\mathrm{R}$ \\
\hline In a group I tease other pupils. & 11 & 06 & 13 & 02 & 1.5000 & .58835 & $\mathrm{R}$ \\
\hline I fight pupils I could easily beat. & 04 & 06 & 10 & 12 & 1.7424 & 91669 & $\mathrm{R}$ \\
\hline Other pupils make fun of me. & 06 & 04 & 10 & 12 & 3.5606 & .76719 & $\mathrm{~A}$ \\
\hline I get hit and pushed because of my anger. & 1200 & 09 & 11 & 02 & 1.7879 & .66830 & $\mathrm{R}$ \\
\hline I threaten to hurt or hit other pupils. & 02 & 08 & 13 & & 2.060 & .82048 & A \\
\hline I hit back when someone hit me . & 04 & 06 & 10 & 12 & 1.2879 & 1.04011 & $\mathrm{R}$ \\
\hline I often cause fight among friends & 00 & 15 & 02 & 15 & 2.0758 & .84791 & $\mathrm{R}$ \\
\hline I destroy classmates books and uniforms. & 04 & 11 & 04 & 14 & 2.5939 & 1.07966 & $\mathrm{~A}$ \\
\hline I frighten pupils with knife or sharp weapon. & 04 & 10 & 06 & 12 & 3.2221 & .6830 & $\mathrm{~A}$ \\
\hline Mean score & 48 & 87 & 89 & 97 & 2.08182 & 0.74066 & $\mathrm{R}$ \\
\hline
\end{tabular}

Aggression as an anti social behaviour influence the academic achievement of students with deviant behaviours

Table 4.1 shows a mean score of 2.18484 with a standard deviation of 0.693022 for the section. Judging from the decision level, the respondents are of the view that aggression as an anti social behaviour influence the academic achievement of students with deviant behaviours at a low extends. 
Bulling as an anti social behaviour influence the academic achievement of students with deviant behaviours

Table 4.2 shows a mean score of 2.08182 with a standard deviation of 0.74066 for the section. Judging from the decision level, the respondents are of the view that bulling greatly influence the academic achievement of students with deviant behaviours.

Table 4.3, Withdrawal scale(Definitely True (DT), probably True (PT), definitely False (DF), probably False (PF)

\begin{tabular}{|l|l|l|l|l|l|l|l|}
\hline Withdrawal scale & DT & PT & DF & PF & 2.6970 & .91095 & A \\
\hline There are several pupils I don't trust & 04 & 06 & 10 & 12 & 2.2879 & .92429 & R \\
\hline Most of my friends are more interesting than I am. & & & & & \\
\hline There is no one that I feel comfortable talking with & 00 & 15 & 02 & 15 & 2.7879 & .95297 & A \\
\hline Most pupils I know don't think highly of me. & 04 & 11 & 04 & 14 & 3.0606 & .82048 & A \\
\hline I feel like I'm not always included by my friends. & 04 & 10 & 06 & 12 & 2.2879 & 1.04903 & R \\
\hline $\begin{array}{l}\text { There is really no one who handling my bad } \\
\text { behaviours }\end{array}$ & 12 & 04 & 11 & 05 & 2.0758 & .84691 & R \\
\hline I prefer to keep to myself & 12 & 04 & 06 & 10 & 2.8939 & 1.03966 & A \\
\hline I feel nobody understands my problem Internatic 09 & 11 & 10 & 02 & 3.2121 & .66830 & A \\
\hline Mean Score
\end{tabular}

\section{Withdrawal}

$x=$ Mean $\quad$ Std Dev $=$ Standard deviation $\quad \mathrm{A}=$ Accepted $\quad \mathrm{R}=$ Rejected

Decision level: $\quad \bar{x}=\frac{4+3+2+1}{4}=\frac{10}{4}=2.5$

The table shows a mean score of 2.584429 with a standard deviation of 0.934899 for the section. Judging from the decision level, the respondents accepted the view that withdrawal amongst students with deviant behaviours greatly negatively influence the academic achievements.

\section{FINDINGS EMERGING FROM INTERVIEWS AND OBSERVATIONS}

Qualitative findings were done through interviews and non-participatory observations. The qualitative findings are presented based on concepts deduced from the research questions.

\section{Student Deviance in School Setup}

In response to the question on problems students and teachers normally face regarding students' welfare, $70 \%$ of the respondents cited poor background and their not having food, stationery, late to school not being able to pay their fees and regular absenteeism from school. Lack of discipline and failure to abide to school rules is a common phenomenon which was observed in the schools. $20 \%$ of the respondents cited parent's negligence as a problem facing children. $30 \%$ highlighted having to walk long distances to school. $10 \%$ cited lack of interest in school work as a problem affecting student welfare. 5\% of the respondents indicated that children who come from child headed households are not stable 


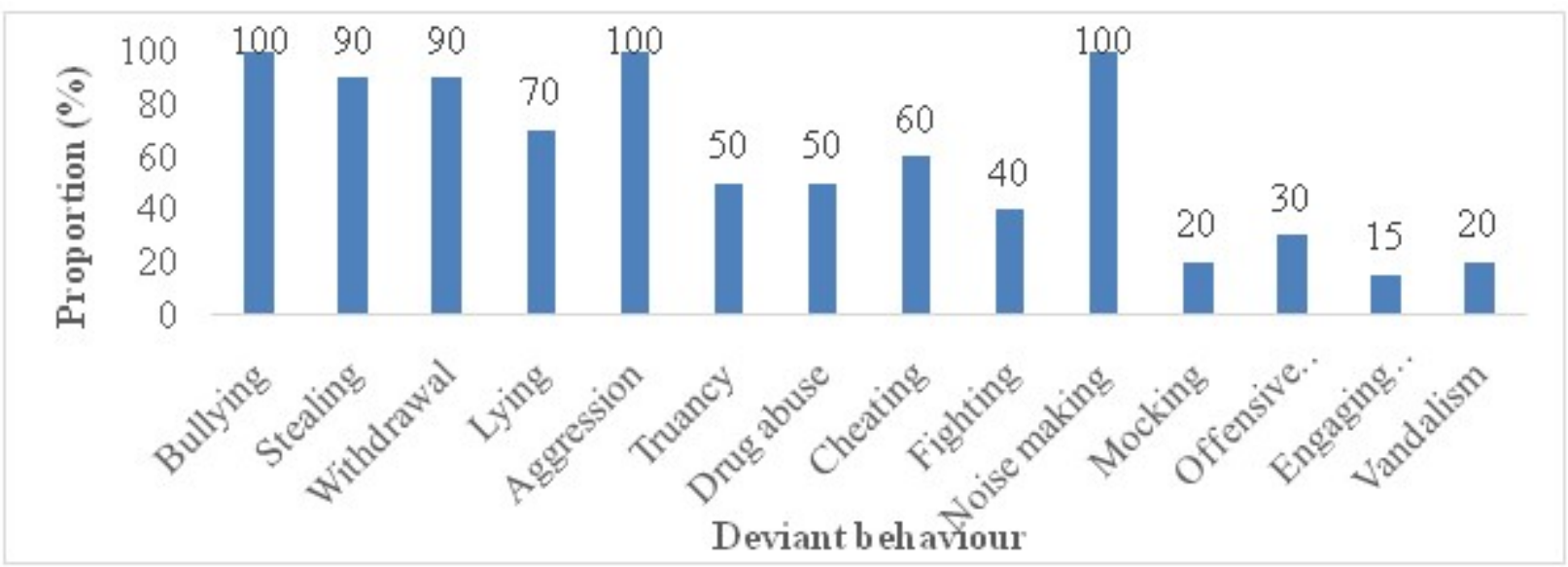

Figure 4.3 Deviant Behaviour in Schools

Beside the three major indicators of deviant behaviour which this study set to measure, through interview with teachers and students, some other indicators came up which necessitated a closer analysis on them. The most common deviant behaviours were bullying, aggression and noise-making as highlighted by $100 \%$ of the respondents. $90 \%$ of the respondents indicated that stealing and social withdrawal is prevalent in their schools. Lying was found to be common in most schools and this was shown by $70 \%$ of the teachers. Drug abuse and cheating were fairly common as indicated by $50 \%$ of the teachers. $40 \%$ of the respondents cited fighting as a deviant behavior in the schools. The use of foul language was uncommon as indicated by $30 \%$ of the respondents. Mocking others and vandalism were seen not that common as only $20 \%$ of the respondents highlighted. The least common deviant behaviour was engaging in love affairs as indicated by $15 \%$ of the teachers. This is because the students are young and have not yet started engaging in love affairs.

\section{Summary of Findings}

The research revealed that the majority of teachers in selected schools in the Limbe I municipality use punishment as one of the means to manage deviance in their classes.

* It was also revealed that indicators of deviant behavior (aggression, withdrawal and bullying) had an influence on the academic achievement of students with deviant behaviours.

* Though punishment comes in numerous forms, teachers share the varying views as regards to the use of and effects of corporal punishment.

* While the problem of corporal punishment was quite prevalent, it was alsow observed that like any other form of punishment, it can equally harm students if not reasonably administered.

A close association between lack of discipline and failure rate/ poor academic $\varpi$ results on the part of students was also established.

* The poor results could be attributed to the inability to administer disciplinaryw measures.

Frequent disruption of the teaching was also observed. Most respondents agreed that instead of beating the students, they would rather send the students to the discipline service. At the office the student is made to wait for hours since the senior discipline master/mistress is involved in many other disciplinary issues.

Most respondents identified gaps related to guidance and counseling. Comments made in support of these gaps were that the teachers were not that professionally knowledgeable in this area so that they cannot really help the students with serious deviant behaviour.

* The data revealed that parents did not have a close relationship with the students of this study. This resulted in lack of close supervision and little attempts to instill proper discipline in these students. Also, students held the view that the parents or relatives' beliefs regarding their own actions seem to negatively impact students' beliefs and values, which were manifested in deviant behaviours. Similarly, students felt that teachers' negative attitude and degrading remarks negatively influenced their behaviours. However, some students felt that their behaviours were attempts to protect themselves against teachers or students who made little attempts to understand their situation.

* The data revealed that deviant students believed that their behaviour was comical and thus, harmless. As such the lack of extracurricular 
activities during school hours forced them to seek alternative ways of occupying their time in an attempt at entertaining themselves, which resulted in engagement in deviant behaviours. Additionally, the students believe their actions to be normal and equate them with the role of a teenager. On the other hand, in an attempt to avoid embarrassment by the teacher and to preserve their reputations they defend themselves, suggesting that their behaviour is the only way they will be heard.

- The data revealed that students held a negative perception of their treatment by teachers. They believed that teachers unfairly treated them, showing favoritism and bias towards non deviants. Similarly, unfair discipline practices were used by teachers, where being deviant was a one way ticket to being blamed for incidents. Additionally, teachers seemed to display little tolerance for deviant students, negatively labeling them. This in turn, accounted for misinterpretations between teachers and the deviants, where at times teachers would over react over trivial issues showing disgust and use aggression in dealing with them.

\section{Educational Implications of the Study}

The findings from this study have research implications. The results evidenced that when multiple behavioral problems are studied simultaneously, it mitigates the varying results from studies that examined the behavioral problems separately. The results here identified the unique effects of various behavioral problems on later academic performance of students. Therefore, more confidence should be given to the results obtained from studies that accounted for the students' confounding behavioral problems. Nevertheless, this study did not examine the combined effects or the possible interaction effects between behavioral problems. Given the importance of how these behavioral variables interact to effect the academic development of students, future studies should investigate the combined effects of behavioral variables as well as replicate the unique effects of various behavioral problems.

Furthermore, the results from this study have implications for practice. Given the limited resources in the educational field, the results from this study may be used to guide educational personnel on how to best utilize resources. This study indicates that special focus should be given to students with individual inattentive behaviors and classrooms with high levels of externalizing behaviors because they are the strongest predictors of academic performance. It may be difficult for teachers to identify the students with higher levels of inattentive behaviors. School psychologist can aid the teachers in providing an early behavioral screening method to identify students who are at-risk for inattentive behavioral problems.

The results in this study indicate that student role performance factors are more critical for both nondeviant and deviant students than family and school factors to affect students' test scores. Family and school factors should not be ignored, but regarded as important factors that affect test scores. In order to achieve higher test scores for both deviant and nondeviant students, policies including all three factors need to be developed. Giving more support to programs for disable students, encouraging students to participate extracurricular activities in school, and increasing family communication with students, such as helping homework or participating school activities, would be policies that might achieve higher test scores. Also, schools should provide safe environments without any learning disruptions.

Teaching at all levels of education is very important and there are certain unprofessional conduct displayed by the teacher in carrying out his/her duty that requires counseling intervention. A few of these include unpreparedness, absenteeism, using inappropriate teaching methods, etc. Unfortunately, most schools in which counselors are posted to work often ignore this aspect of the work of a counselor, and the teachers themselves may not be willing to undergo counseling with those whom they consider as their colleagues in the teaching profession. Therefore, it is very important that counseling is given its prominent position within the school system to allow the total development of pupils and students as well as to correct some of these unhealthy behaviours of the teachers. This is because the actions taken by teachers which have a negative effect on the students' academic performance might remain, unless counselors are allowed to do their job. Therefore, school heads should refer such disciplinary cases to a trained counselor for individual or group counseling encounter, especially in a situation where teachers' behavioural disposition may affect the students' academic performance negatively. Since behaviour is a product of learning, it can also be unlearned in order to have proper functioning of the education system. It 
is therefore advocated that teachers who are undisciplined or acting in a manner that is not expected of them should be made to undergo behaviour therapy.

Finally, the significant effects of classroom-level behavioral problems reveal that the contextual environment of the students helps determine their academic success in the future. Students being placed in a classroom environment where there are high levels of externalizing behaviors such as physical aggression, verbal teasing, defiance of teachers, etc. during the early elementary school years signal an increase in academic struggles and minimizes successful achievement years afterwards. The placement of the students' classroom for the academic year is an important decision because the students will remain in that classroom surrounded by their peers for the whole school year. To prevent the negative effects of being in an aggressive classroom context, attention should be given to the even distribution of aggressive and disruptive students among classrooms. Ultimately, the practice of clustering these disruptive students together in one classroom should be avoided. Furthermore, it is necessary to address the individual externalizing behaviors of the students within these classrooms as well as addressing the whole group level of externalizing behavioral problems.

\section{Recommendations}

In light of the findings presented in this study, the following recommendations are suggested. Firstly, the need to educate parents on the role that they play in the lives of their children is imperative to bridging the distance between parent and child, in communicating positive reinforcement, guidance, support and love. As such, the need to put pre-emptive (not reactionary) measures in place should entail the introduction of parenting classes from as early as elementary school into secondary school, so as to inculcate ones responsibility throughout every stage of his life till he/she is able to fully function on his/her own as an adult.

Secondly, the introduction of conflict management sessions once a week, for the five year period in the secondary school system should be structured into instructional time. This would ensure that students are equipped with the tools necessary to deal with conflict as they exist on a daily basis.
Thirdly, schools need to effectively introduce extracurricular activities during school hours so as to offer students opportunities to actively engage in constructive skill building activities, possibly sports. The Ministry of Education needs to supply schools with the necessary resources, facilities and equipment that would aid in creating constructive and productive school settings. In addition, mandatory teacher training should be given to teachers prior to their placement into schools as well as on-going training to ensure that teachers are au courant with techniques and strategies that would assist in dealing with deviant students.

\section{Conclusion}

Based on the findings of the study it has been concluded that truant/deviants behaviors have profound effects on the academic achievement of secondary school students in selected schools. However, these effects tend to be negative as truancy could lead to poor performance or failure in terminal examinations. Also, it has the tendency to increase the rate of dropouts in secondary schools in the area. Therefore, Merton's Anomie theory, which supposes that socially accepted goals such as education and hard work could assure success seem to agree with the findings. Thus, students who study hard can achieve more academically, while those who do not are bound for failure.This study which employed a triangulated descriptive survey study methodology to the study of deviant behaviour. The present study was designed to explore deviant students' perceptions of their behaviour and how such behaviors influence students' academic achievements. Results showed that parenting practices and negative teacher attitude are instrumental in shaping deviant behaviours. However, negative teacher attitude seemed to have a greater influence on deviant behaviour. The study found that parents who share a poor relationship with their children tend to promote deviant behaviours through a lack of monitoring and supervision of their activities. Of equal importance was the finding that teachers' attitudes directly foster or eradicate deviant behaviours in students. Teachers who hold negative perceptions of students and who engage in unfair practices, tend to encourage deviancy.

Based on these findings it would appear that deviant students are not solely to be held accountable for their behaviours. Other factors, which are out of the control of the child do impinge and play vital roles in helping 
to shape and stabilize deviant behaviours. Also, it would appear plausible to conclude that the theory of reasoned action serves to highlight how the beliefs of others can impact on one's attitude, intentions and finally, actions. Therefore, teachers and administrators should seek to utilize strategies that aim at reducing and eliminating deviant behaviours in the school, by showing sensitivity and compassion for students considered deviant. Without ample training workshops to assist teachers in counteracting deviancy, the fundamental purpose of schooling that being, learning, will be lost.

\section{REFERENCES}

1. Englewood Cliffs, NJ. Ary, D., Duncan, T., Biglan, A., Metzler, C., Noell, J. and Smolkowski, K. (1999). Development Of Adolescent Problem Behavior. Journal of Abnormal Child Psychology, Vol. 27, No. 2, pp. 141-150.

2. Awang, M., Ahmad, A. and Ali, M. (2013). Professional Teachers' Strategies for Promoting Positive Behaviour in Schools. Journal title: Asian Social Science. Volume: 9. Issue: 12.

3. Damron-Bell, J. (2011). The Development Of Deviant Behavior In Adolescents: The Influence Of Student Characteristics And School Climate. Department of Educational and Counseling Psychology University of Louisville, Kentucky.

4. Griffin, K., Botvin, G., Scheier, L., Diaz, T., \& Miller, N. (2000). Parenting Practices as Predictors of Substance Abuse, Delinquency, and Aggression Among Urban Minority Youth: Moderating Effects Of Family Structure And Gender. Psychology of Addictive Behaviours, Vol. 14, No. 2, 174-184. Educational Publishing Foundation.

5. Herrero, J., Estevez, E. and Musitu, G. (2006). The relationships of adolescent school-related deviant behaviour and victimization with psychological distress: Testing a general model of the meditational role of parents and teachers across groups of gender and age. Journal of Adolescence 29, 671-690.

6. Hoeve, M., Dubas, J., Eichelsheim, V., Laan, P., Smeenk., \& Gerris, J. (2009). The relationship between parenting and delinquency: A metaanalysis. J Abnorm Child Psychol 37: 749- 775.

7. Hulelai, K. \& Matsolo, W. (2011). Perceptions of Agriculture Science Teachers Regarding Negative
Deviant Behaviours of Students in Senior Secondary Schools in Botswana. International Journal of Scientific Research in Education, Vol. 4(1), 47-56.

8. Ibolya, L. and Graham, T. (2007). Parental Shaming and Adolescent Delinquency: A Partial Test of Reintegrative Shaming Theory. Australian and New Zealand Journal of Criminology. Volume: 40. Issue: 2. Australian Academic Press Pty. Ltd.

9. Jackson, C. (2004). Laddishness and Self-Worth Protection. UK Data Archive.

10. Jacob, S. and Furgerson, S. (2012). Writing Interview Protocols and Conducting Interviews: Tips for Students New to the Field of Qualitative Research. The Qualitative Report 2012 Volume 17, T\&L Art. 6, 1-10.

11. Lodico, M., Spaulding, D. \& Voegtle, K. (2006) Methods in educational research: From theory to practice. San Francisco: Jossey-Bass. Lopez, E., Perez, S., Ochoa, G. and Ruiz., D. (2008). Adolescent aggression: Effects of gender and family and school environments. Journal of Adolescence 31: 433-450. Elsevier Ltd.

12. Moswela, B. (2006). Boarding Schools as Perpetrators of Students' Behaviour Problems. J. Soc. Sci., 13(1): 37-41(2006). University of Botswana, Department of Educational Foundations, Bag 0022, Gaborone, Botswana.

13. Munn, P., Johnstone, M., Sharp, S. \& Brown, J. (2007). Violence in Schools: Perceptions of Secondary Teachers and Head teachers Over Time. The University of Edinburgh. International Journal on Violence and Schools.

14. Munn, P. and Lloyd, G. (2005). Exclusion and excluded pupils. British Educational Research Journal Vol. 31, No. 2, April 2005, pp. 205-221. Wiley Publishing. Accessed: 13/04/2014.

15. Olugbode, A. (2012). Effect Of Social Problems On The Academic Performance And Social Adjustment Of Senior Secondary Students In Shomolu Education District Ii Of Lagos State. Website: Academia.Edu. Dec 15th 2012.

16. Patterson, G. R., Capaldi, D. M., \& Bank, L. (1991). An early starter model for predicting delinquency. In D. J. Pepler \& K. H. Rubin (Eds.) The development and treatment of childhood aggression (pp. 139-168). 
17. Ritchie, J., Lewis, J. \& Elam, G. (2003): Designing and selecting samples. In: J. Ritchie \& J. Lewis, eds. Qualitative research practice. A guide for social science students and Researchers. Thousand Oaks, CA: Sage Publications: 77-108.

18. Sanches, C., Gouveia-Pereira, M. \& Carugati, F. (2011). Justice judgements, school failure, and adolescent deviant behaviour. British Journal of Educational Psychology 606-621.

19. Simons, R., Whitbeck, L., Conger, R. \& Conger, K. (1991). Parenting Factors, Social Skills, and Value Commitments as Precursors to School Failure, Involvement with Deviant Peers, and Delinquent Behavior. University of Nebraska. Lincoln. Sociology Department, Faculty Publications. Paper 93. Journal of Youth and Adolescence 20:6 (1991), pp. 645- 664. Plenum Publishing Corporation.

20. Thompson, B. (2009) An Investigation into the relationship among certain psychosocial variables and classroom disruptive behaviours among adolescents in barbadian secondary schools .

21. Thompson, G. W. \& Warnick, B.K. (2007). Integrating science into the Agricultural Education curriculum: do science and agriculture teachers agree? Journal of Agricultural Education.

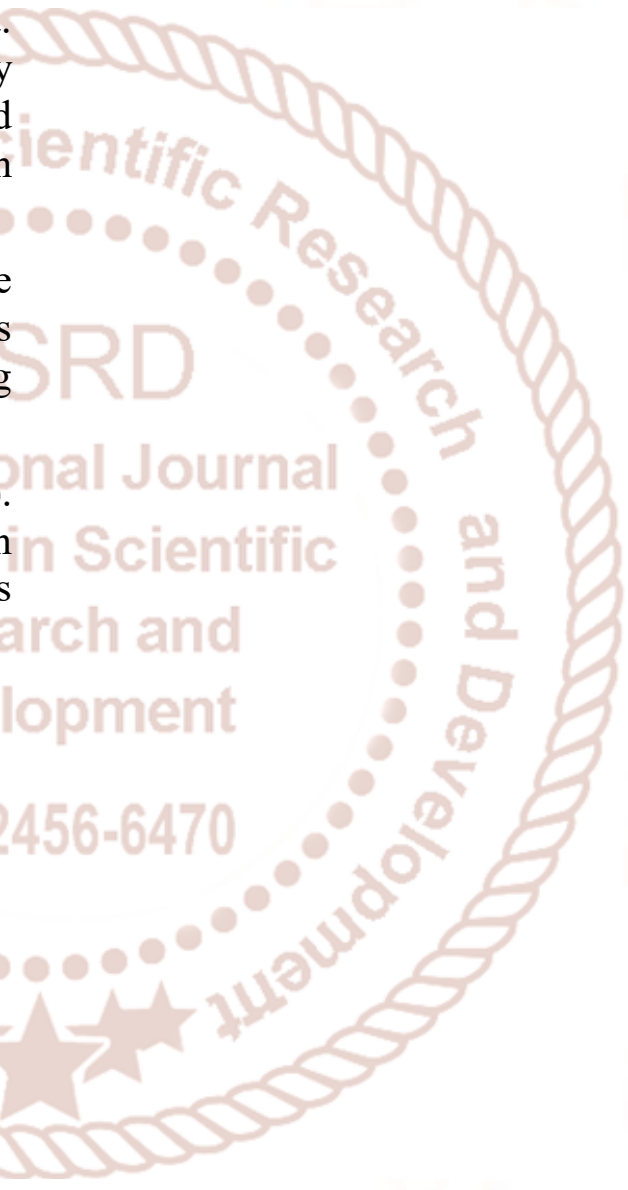

